\title{
Performance Analysis of Various Ad Hoc Routing Protocols in MANET using Variation in Pause Time and Mobility Speed
}

\author{
Rajeev Paulus \\ Assistant. Prof. ECED. \\ SSET, SHIATS, Allahabad \\ Priyanka D.Kumar \\ Assistant. Prof., ECED \\ SSET, SHIATS, Allahabad
}

\author{
Prinu C.Philiips \\ Teaching Assistant \\ SSET,SHIATS, Allahabad
}

\author{
Anil Kumar \\ Assistant. Prof. \\ SSET, SHIATS,Allahabad
}

\begin{abstract}
A Mobile Ad-Hoc Network (MANET) is a collection of wireless mobile nodes that communicates with each other without using any existing infrastructure, access point or centralized controller. In MANET, as nodes moves in and out of the network, the topology of the network changes frequently and thus, routing becomes a challenging task. A variety of routing protocols with varying network conditions are analyzed to find an optimized path from a source to destination. In this article a performance comparison of four popular mobile ad-hoc network routing protocols i.e. Ad hoc On-demand Distance Vector (AODV), Dynamic Source Routing (DSR), Optimization Link State Routing (OLSR) and Zone Routing Protocol (ZRP) is presented with variable pause time. A network simulator QualNet 6.1. from scalable networks is used to evaluate the performance of these protocols. The performance analysis is based on different network metrics such as Average End to End delay (s), Average Jitter(s), Throughput and Packet delivery ratio.
\end{abstract}

\section{Keywords}

MANET, AODV, DSR, OLSR , ZRP, QualNet 6.1.

\section{INTRODUCTION}

Over recent time Mobile Adhoc Network (MANET) are widely uses in many applications. Mobile Ad Hoc Networks are the self-organizing and self-configuring wireless networks which do not rely on a fixed infrastructure and has the capability of rapid deployment in response to application needs. Nodes of these networks function as routers which discover and maintain routes to other nodes in the network [1]. A MANET can be used for both unicast and multicast type of communication. Conventional protocols used for fixed infrastructure networks cannot be efficiently used for mobile ad-hoc networks, so that MANET requires routing protocol other than conventional ones [2].In MANETs some of protocols used for comparison are: AODV [3,4], DYMO [5],DSR[6,9,13], OLSR [7,11], ZRP [8,9,14],FSR [10] etc. Among all AODV, DSR, DYMO and ZRP are well known popular routing protocols and have been standardized by the IETF MANET Working Group. The three most popular reactive routing protocols for MANETs namely AdHoc On-demand Distance Vector (AODV), Dynamic Source Routing (DSR) and Dynamic MANET Ondemand (DYMO), find route only when node have data to send. It avoids the need of frequent link and route updates therefore substantially reduces energy consumption when the traffic load is light or the network mobility is high. All of the above discussed protocols are operating only in Network layer. This paper evaluates the performance comparison of AODV, DSR, OLSR and ZRP protocols under different network conditions. The rest of the paper is organized as follows: Section-2 Related works; Section-3 Overview of Routing Protocols; Section-4 Simulation Setup, Section-5 Results and Discussion and performance comparison graphs. Finally, Conclusion is presented in Section-6.

\section{RELATED WORK}

S. R. Raju, et.al [9] proposed an algorithm to provide improved quality of service via hybrid routing protocol ZRP. They used QualNet version 4.5 and evaluated the performance in ZRP,AODV,DSR to compare QoS parameters viz., throughput, number of bytes received, number of packets received, average end-toend delay and the time at which first packet has been received for DSR, AODV and ZRP. Their result showed that ZRP was not up to the task and it performed poorly throughout all the simulation sequences. Their work did not include DYMO protocol and used fixed mobility speed 1-8 mps and pause time but they use different network sizes with different nodes.

Gaurav Sharma, et.al [2], analyzed the performance of AODV, DSR and DYMO under the effect of two shadowing model, as Constant and Lognormal used well known network simulator Qualnet 5.2. They took 75 nodes with different maximum speed and analyzed various performance parameters such as throughput, number of bytes received, average end-to-end delay. They observed that for constant model, AODV outperforms the other two protocols. DSR showed the worst performance. But for the log-normal, DSR showed better performance than AODV and DYMO.

P. K. Maurya, et.al [13] compared ZRP, AODV, DYMO and DSR using Qualnet 5.2. They analyzed the throughput, average jitter, average end-to-end and packet delivery ratio in two different phases, one phase was used to analyze in pause times and in second phase they varied the maximum speed of nodes in scenarios. ZRP had lower throughput, lower PDR than AODV, DSR and DYMO which makes itself out of the race. In second phase AODV gave better performance than DYMO and ZRP but lower than DSR. Over all they could conclude that AODV performed better under different network conditions.

Subramanya, et.al [11] compared proactive (OLSR), reactive (AODV, DSR, LAR) and hybrid (ZRP) routing protocols for stationary and mobile nodes by varying the node density $(25,50,75,100,150,200$ and 250) using Qualnet 5.0.2 network simulator. They considered AODV, DSR, LAR, and OLSR, ZRP routing protocols 
for analysis and varied node numbers along with mobility speed. They took parameters such as throughput, average jitter, average end-to-end delay and packet delivery ratio for the analysis.

\section{OVERVIEW OF ROUTING PROTOCOLS}

\subsection{Ad-hoc On Demand distance Vector routing protocol (AODV)}

AODV $[3,4]$ is a reactive routing protocol. The AODV Routing protocol [13] uses an on-demand approach for finding routes, that is, a route is established only when it is required by a source node for transmitting data packets. In AODV, whenever a source node needs a route to a destination node for which it does not have a route; it broadcasts a route request (RREQ) packet to all its neighbors. A neighbour receiving a RREQ may send a route reply (RREP) packet if it is either the destination or if it has an unexpired route to the destination. Along the path back to the source, intermediate nodes that receive the RREP create forward route entries for the destination node in their routing tables. In order to maintain the routes, AODV normally uses link layer feedback and hello packets. When a link break in an active route is detected by the above mentioned method, the node notifies this link break by sending a route error (RERR) packet to the source node. Upon receiving the RERR packet, the source node newly initiates the procedure for route discovery [4].

\subsection{Dynamic Source routing protocol (DSR)}

The DSR protocol $[6,9]$ is a simple and efficient routing protocol designed specifically for use in multi-hop wireless ad-hoc networks of mobile nodes. DSR allows the network to be completely self-organizing and selfconfiguring, without the need for any pre-existing network infrastructure. DSR is composed of the two mechanisms of Route Discovery and Route Maintenance [6]. When a mobile node has a packet to send to some destination, it first checks its route cache to decide whether it already has a route to the destination. If it has an unexpired route, it will use this route to send the packet to the destination. On the other hand, if the cache does not have such a route, it initiates route discovery by broadcasting a route request packet. Each node receiving the route request packet searches throughout its route cache for a route to the intended destination. If no route is found in the cache, it adds its own address to the route record of the packet and then forwards the packet to its neighbors. This request propagates through the network until either the destination or an intermediate node with a route to destination is reached. Whenever route request reaches either to the destination itself or to an intermediate node which has a route to the destination, a route reply is unicasted back to its originator. Route is maintained by using route error packets and acknowledgment

\subsection{Optimized Link State Routing (OLSR)}

OLSR [7, 11] is proactive and table driven routing protocol. It uses periodic messages to update the topological information of the network among the nodes. The nodes exchange this information to establish a route to the destination node in the network. The advantage of this scheme is that routes are immediately available at each node to the destination node [11].It reduces the possible overhead in the network protocol and are used to multipoint relays (MPR). Reducing the time interval for the control messages transmission brings more reactivity to the topological changes [7,11].OLSR protocols is suitable for large and dense area of networks.

\subsection{Zone Routing Protocol (ZRP)}

ZRP $[8,9,13]$ is a hybrid protocol, it is combination of reactive and proactive routing protocols. ZRP is proposed to reduce the control overhead of proactive routing protocols and decrease the latency caused by routing discover in reactive routing protocols [9]. ZRP defines a zone around each node consisting of its kneighborhood (e. g.k=3). In ZRP, the distance and a node, all nodes within -hop distance from node belongs to the routing zone of node [9]. ZRP is formed by two sub-protocols, a proactive routing protocol: Intra-zone Routing Protocol (IARP) [8, 13] is used inside routing zones and a reactive routing protocol: Inter-zone Routing Protocol (IERP) $[8,13]$ is used between routing zones, respectively. The Inter-zone Routing Protocol (IERP) [8, 13 ] is used to communicate between nodes of different routing zones. It is a reactive routing protocol and the route discovery process is only initiated when needed or on demand. This makes route finding slower, but the delay can be minimized by use of the Bordercast Resolution Protocol (BRP).

\section{SIMULATION SETUP}

Simulations is carried out on QualNet version 6.1[12] in this paper we have evaluated the performance variation of MANET Routing Protocols AODV, DSR,OLSR and ZRP by changing the maximum speed and pause time of nodes with which it can move in the network, over an area of $750 \times 750 \mathrm{~m}^{2}$. Beside with variation in maximum speed of nodes and pause time of nodes. Among various nodes application of Constant Bit Rate is applied. All the nodes in the depicted scenario are given a mobility using the protocol of Random waypoint mobility model. Simulation parameters are shown in table 1 and simulation results are shown in figures from 1 to 8 . With the help of simulation results we have analyzed Average Jitter, Packet delivery ratio, Throughput, and End-to-End delay for the given protocol. These parameters are defined below:

\subsection{Packet delivery ratio}

It is the fraction of number of packets received by the destination to the total number of packets generated by all the devices in the network. It is the measure of reliability for a particular protocol and network used.

\subsection{Throughput}

It is defined as the information in bits which is received successfully by the destination in an average time. Its unit is bps.

\subsection{Average End-to-End delay}

It is the time elapsed when a packet is sent from the source node and is successfully received by the destination node. It includes delays as delay for route discovery, propagation time, data transfer time, and intermediate queuing delays.

4.4 Average Jitter

It is the difference in the arrival time of the packets. 
Table.1 Simulation Parameters

\begin{tabular}{|l|l|}
\hline \multicolumn{1}{|c|}{ Parameter } & \multicolumn{1}{c|}{ Value } \\
\hline Simulation time & $2.4 \mathrm{GHz}$ \\
\hline Channel frequency & 802.11 \\
\hline MAC protocol & $802.11 \mathrm{~b}$ \\
\hline Physical layer Radio-type & 512 bytes \\
\hline Packet size & UDP \\
\hline Transport layer protocol & CBR \\
\hline Application & AODV,DSR,OLSR,ZRP \\
\hline Routing Protocols & Two Ray \\
\hline Pathloss Model & 25 \\
\hline No. of nodes & Constant \\
\hline Shadowing Model & $(5,10,15,20), 10$ \\
\hline Maximum Speed(mps) & \multicolumn{1}{c|}{ Omps } \\
\hline Minimum Speed & $15,(10,20.25,30)$ \\
\hline Pause Time(sec) & 5 packet per second \\
\hline $\begin{array}{l}\text { Rate of transmission of } \\
\text { packet }\end{array}$ & \\
\hline
\end{tabular}

\section{RESULTS AND DISCUSSION}

Fig.1 shows that variation of throughput against pause time, it can be observed that AODV and DSR attain same throughput value but OLSR has throughput increasing with varying pause time and it is decreased for 10sec pause time and ZRP has lowest throughput but for $25 \mathrm{sec}$ pause time ZRP throughput increases.

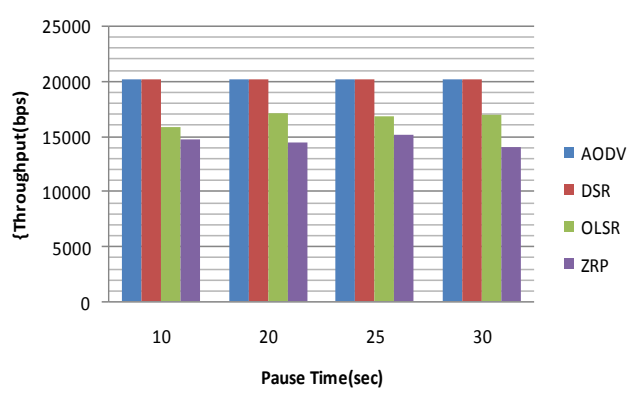

Fig.1 Throughput vs Pause Time

Fig. 2, shows that variation of average jitter against pause time, it is observed that AODV perform well in all pause time, ZRP jitter variation is very small but ZRP performs well than DSR and OLSR protocol jitter are 10 and $25 \mathrm{sec}$ pause time decreases and at 20 and $30 \mathrm{sec}$ pause time it increases.

Fig.3, shows the variation of average end to end delay against pause time of nodes and it is observed that AODV and ZRP has lowest value of average end-to-end delay with all most constant value, but OLSR perform worst for 20 and $30 \mathrm{sec}$ pause time.DSR has lesser decreases in end-to-end delay with varying pause time

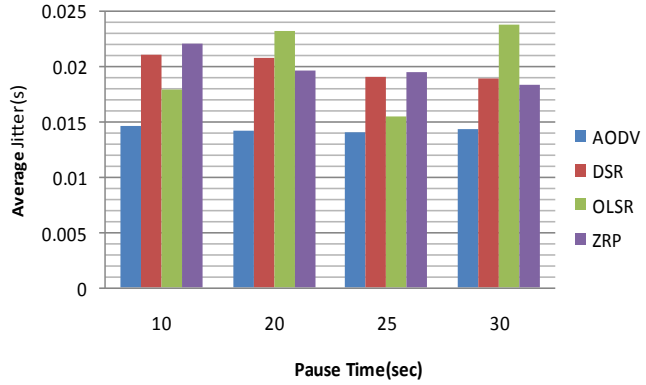

Fig.2 Average Jitter vs Pause Time

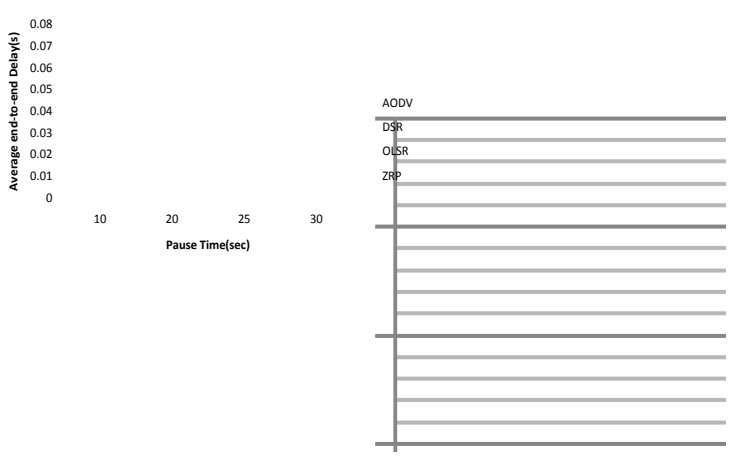

Fig.3 Average end-to-end delay vs. Pause Time

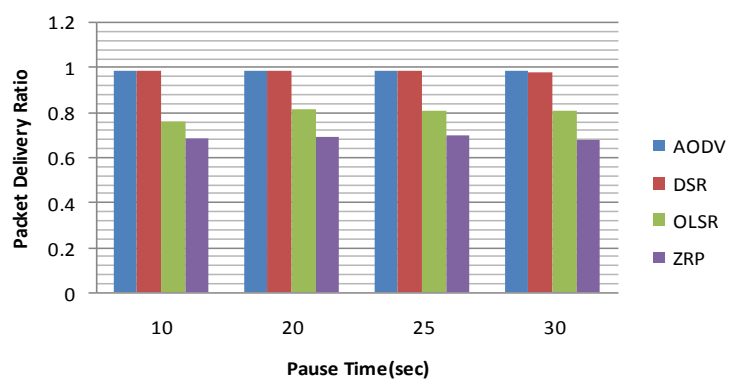

Fig.4 Packet delivery Ratio vs Pause Time

Fig.4, shows the variation packet delivery ratio against pause time, It is observed that for AODV and DSR packet delivery ratio are almost constant but ZRP shows the lowest packet delivery ratio. OLSR shows increase in PDR with increase in pause time.

Fig.5 shows that variation of throughput against pause time, it can be observed that AODV and DSR throughput are almost same but for DSR throughput decrease at 15 mps. OLSR throughput is better than ZRP and it is decreasing when there is increase in the maximum speed. ZRP has lowest throughput and it is decreasing when increase in the maximum speed.

Fig.6 shows that variation of average jitter against maximum speed, it is observed that AODV has better performance at all maximum speed and it is increasing with increase in the maximum speed.DSR shows worst performance and it is increasing when maximum speed increases. OLSR has lesser average jitter than ZRP and DSR.ZRP gives increased average jitter for $10 \mathrm{mps}$, other than ZRP average jitter decreases for remaining protocols when there is increase in the maximum speed 


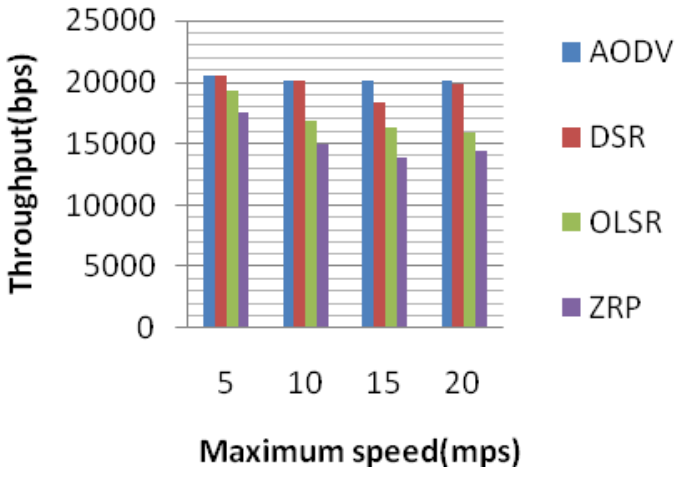

Fig. 5 Throughput vs Maximum speed

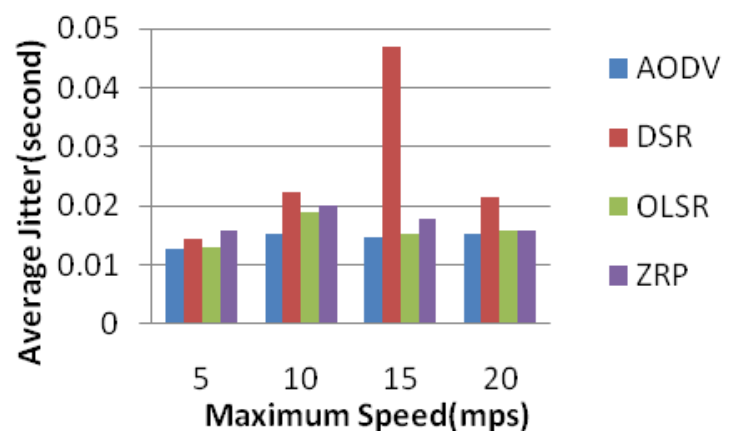

Fig.6 Average Jitter vs. maximum speed

Fig.7, shows the variation of average end to end delay against maximum speed of nodes and it is observed that AODV,DSR and ZRP has small value of average end-toend delay with constant values of maximum speed, but DSR shows worst performance when its maximum speed increases.

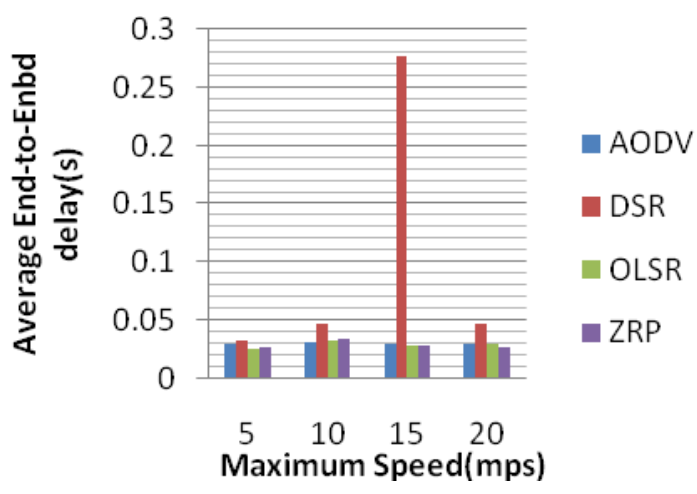

Fig.7 Average end-to-end delay vs Maximum speed

From Fig. 8 shows that variation of packet delivery ratio against maximum speed, it can be observed that AODV and DSR packet delivery ratio almost same but DSR packet delivery ratio decreases for $15 \mathrm{mps}$. OLSR packet delivery ratio is better than ZRP and it decreases when increase in the maximum speed. ZRP has lowest packet delivery ratio and it decreases when there is increase in the maximum speed.

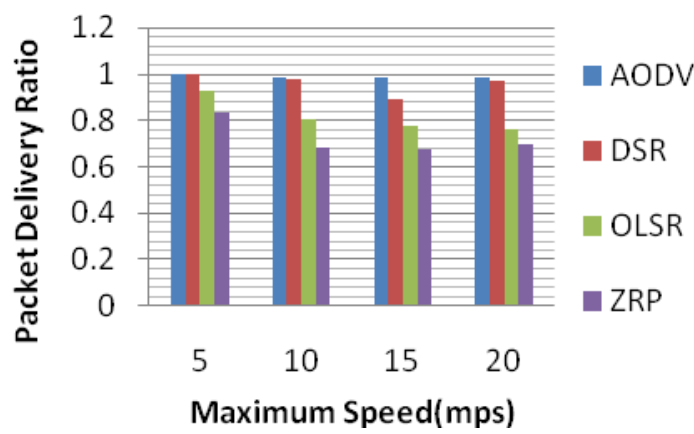

Fig.8 Packet delivery ratio vs Maximum speed

\section{CONCLUSIONS}

This paper presents a performance difference of AODV, DSR, OLSR and ZRP routing protocol for mobile adhoc networks with variable pause time. We measure End to End delay (s), Average Jitter (s), Throughput and Packet delivery ratio as performance metrics. Our simulation results shows AODV performance is best under all performance metrics for pause time and maximum speed network condition.DSR throughput and packet delivery ratio is better than OLSR and ZRP.OLSR shows the worst performance for average jitter and average end-to-end delay with the varying pause time. ZRP has lower throughput, lower PDR than AODV, DSR and OLSR with the varying pause time and maximum speed.DSR shows the worst performance for average jitter and average end-to-end delay. In future, this paper can be enhanced by analyzing the other MANET routing protocols under real-world scenarios.

\section{REFERENCES}

[1] A.K.Maurya, D. Singh," Simulation based Performance Comparison of AODV, FSR and ZRP Routing Protocols in MANET", Volume 12No.2,pp 23-28, November 2010,IJCA (0975 8887).

[2] Gaurav Sharma ,V. Sahu, P.K. Maurya, R.Paulus," Analyzing the Effect of Constant and Lognormal Shadowing Model on Ad-hoc Routing Protocols" Volume 66- No.8,IJCA,March,pp-16-19,Mar 2013.

[3] C.E. Perkins and E.M. Royer, "Ad-hoc On-Demand Distance Vector Routing", Proceeding of 2nd IEEE Workshop, Mobile Computing System Applications, pp:90-100, 1999.

[4] Perkins, E. Belding-Royer, and S. Das, "Ad hoc OnDemand Distance Vector (AODV) Routing, "draftietf-manet-aodv-13.txt, Feb. 2003.

[5] I.Chakeres, C.Perkins, "Dynamic MANET OnDemand (DYMO) Routing," IETF Internet-Draft, draft-ietf-manet-dymo-23, pp. 20-25, October.2012.

[6] J.Broch, D. Jhonson, and D.Maltz, "The dynamic source routing protocol for mobile adhoc networks for IPv4" IETF RFC 4728, Feb 2007.

[7] P.Jaquet, P. Muhlethaler and Aqayyum. "Optimized Link State Routing Protocol”, IETF Draft, draft-ietfmanet-olsr-06.txt. 
[8] Z J. Haas, M. R. Pearlman, and P. Samar, "The Zone Routing Protocol (ZRP) for Adhoc Networks", draft-ietf-manet-zone-zrp-04.txt.July 2002.

[9] S. R. Raju and J.Mungara"Performance Evaluation of ZRP over AODV and DSR in Mobile Adhoc Networks Using Qualnet'ISSN 1450-216X Vol.45 No.4 (2010), pp.651-667, European Journal of Scientific Research, 2010.

[10] Mario Gerla, Xiaoyan Hong, Guangyu Pei," Fisheye State Routing Protocol (FSR)", IETF, Draft, draftietf-manet-fsr-03.txt, 2002.

[11] Subramanya Bhat.M, Shwetha.D and Devaraju.J.T"A Performance Study of Proactive, Reactive and Hybrid Routing Protocols using
Qualnet Simulator "Volume 28-No.5, IJCA. Aug. 2011.

[12] The QualNet simulator, www.scalablenetworks.com.

[13] Prashant Kumar Maurya, Rajeev Paulus,A.K. Jaiswal ,Mahendra Srivastava, "Performance Analysis of ZRP over AODV, DSR and DYMO for MANET under Various Network Conditions using QualNet Simulator" Volume 66-No.17, IJCA (0975 - 8887),March.2013.

[14] K.Suresh and K.Jogendra "Comparative Performance Study of Zone Routing Protocol over AODV and DSR Routing Protocols on Constant Bit Rate (CBR)" Volume 45- No.4, IJCA (0975 8887), May 2012. 